\title{
Conmutación y experiencias de viaje en el sur de chile. Prácticas de movilidad de habitantes de ciudades intermedias menores
}

\author{
Commuting and travel experiences in the south of Chile. Mobility practices of minor intermediate \\ cities
}

\author{
Alejandra Lazo $^{\mathrm{a}}$ y Hernán Riquelme Brevis ${ }^{\mathrm{b}}$
}

\section{Historial del artículo Recibido:}

16 de septiembre de 2019. Aceptado:

8 de noviembre de 2019.

\author{
a Universidad de Los Lagos, Osorno, Chile. Correo electrónico: alejandra.lazo@ulagos.c \\ b Universidad Autónoma de Chile, Santiago, Chile. \\ Universidad Arturo Prat, Santiago, Chile.
}

\section{Palabras clave}

Ciudad intermedia menor, conmutación, experiencias de viaje

\begin{abstract}
Resumen
El presente artículo analiza las experiencias de conmutación de habitantes de las comunas de La Unión y Río Bueno, sur de Chile, que se desplazan en diversos dispositivos de transporte con el objetivo de desarrollar sus respectivas actividades cotidianas. A partir de la utilización de métodos móviles, se logró analizar y explorar las dinámicas cotidianas de conmutantes en directa relación con las ciudades habitadas y su conformación territorial, geográfica y espaciotemporal. Dentro de los hallazgos destacan aspectos que tensan y proponen rupturas respecto a las experiencias de viaje entre ciudades intermedias e intermedias menores. Asimismo, existen narrativas de la movilidad que se asocian a las transformaciones corporales y mentales que experimentan los conmutantes durante el tiempo-espacio dedicado a la organización y desarrollo de las prácticas de movilidad. Por último, se constató la existencia de prácticas de movilidad propias de la cultura de los habitantes de estos territorios, con tiempos, ritmos y rituales que se distancian de las experiencias de movilidad contraídas en espacio netamente urbanos.
\end{abstract}

\section{Keywords}

Commuting, minor intermediate city, travel experiences

\section{Abstract}

The present article analyzes the commuting experiences of inhabitants from the communes of La Union and Río Bueno in the south of Chile, who use different means of transportations to develop their respective daily activities. By using mobile methods, it was possible to analyze and explore the daily dynamics of the commuters directly associated with the inhabited cities and their territorial, geographical and time-space disposition. Among the findings, it can be highlighted certain aspects that strain and suggest ruptures in the travel experiences among intermediate and minor intermediate cities. Furthermore, new mobility narratives were found that are associated with body and mind transformations experienced by the commuters during a time-space dedicated to the organization and development of the mobility practices. Finally, it was confirmed the existence of mobility practices that are typical of the culture of the inhabitants of these territories, including differences in time, rhythm and rituals from the mobility practices acquired in solely urban spaces. 


\section{Introducción}

En sociedades globales, caracterizadas por constantes flujos y movimientos, resulta cada vez más usual que el lugar de trabajo y la residencia se encuentren separados por grandes distancias. En este contexto, la movilidad por motivos laborales es vital dentro de la organización de las actividades cotidianas, las experiencias de viaje y las prácticas de movilidad.

Aunque durante el último tiempo la producción científica nacional que tiene por objetivo analizar la movilidad cotidiana de la población ha centrado sus esfuerzos en lo que respecta a ciudades metropolitanas e intermedias mayores, paulatinamente se han desarrollado investigaciones respecto a las experiencias de movilidad en ciudades intermedias e intermedias menores, y también en territorios no metropolitanos (Lazo \& Carvajal, 2017; Riquelme \& Lazo, 2019; Salazar, Fonk \& Vergara, 2018). Evidentemente, estos trabajos incorporan técnicas de investigación que permiten profundizar aspectos propios de la cultura y geografía de estos territorios, lo cual conlleva considerar lugares, distancias, medios de transporte y ritmos que se distancian de las clásicas divisiones entre lo urbano y lo rural, para posibilitar la incorporación de elementos interurbanos, rurales e inclusive interculturales respecto a las prácticas de movilidad en el sur de Chile.

El presente trabajo, nutriéndose de la literatura de la conmutación, abre la posibilidad de examinar cómo en pequeños territorios se construyen redes y ensambles de movilidad a partir de las necesidades y objetivos de personas que viajan en distintos medios de transporte. No obstante, las similitudes y diferencias que pueden encontrarse en el relato y la práctica de los sujetos abren relevantes interrogantes que permiten plantear nuevos escenarios para el estudio de la conmutación en lugares donde la carencia de empleo obliga a que sus habitantes deban desplazarse a otras ciudades con el objetivo de acceder al trabajo y servicios variados.

El naciente interés por estudiar las prácticas de conmutación desde una perspectiva cualitativa en Latinoamérica permite explorar y analizar las dinámicas de conmutación de ciudades intermedias menores en directa relación con las actividades cotidianas. Los objetivos de nuestra investigación se ciñen a la reconfiguración de las barreras urbano-rurales, lo que da paso a movilidades que se desarrollan en ambientes caracterizados por experiencias de viaje dificultosas y en dispositivos de transporte propios de los territorios del sur del país.
Este artículo está compuesto de cuatro secciones. En la primera parte, se desarrolla una discusión conceptual respecto a investigaciones que han planteado la movilidad vinculada a motivos laborales, que destaca el panorama global y enfatiza en aspectos teóricos y metodológicos de la conmutación. En la segunda parte, se explica la metodología utilizada en el estudio, así como las técnicas de investigación desarrolladas en la recopilación de datos. En la tercera sección, se presentan la discusión y análisis de los resultados del trabajo de campo. Finalmente, se entregan conclusiones con el objetivo de pensar las prácticas de conmutación en ciudades intermedias menores, así como su relación con las experiencias y necesidades de habitantes de territorios con características socioculturales propias del sur de Chile.

\section{Movilidad pendular, conmutación y traslados de larga distancia}

Durante las últimas décadas surgen múltiples perspectivas que explican cómo se construyen las movilidades, movimientos y desplazamientos por factores vinculados al trabajo. En términos conceptuales, existen matices entre las definiciones explicativas del movimiento y la movilidad humana. Para los fines de este artículo, surgen tres conceptos que permiten comprender la movilidad por motivos laborales, estos son: movilidad pendular por trabajo, conmutación (intrarregional) y traslados de larga distancia.

En primer lugar, la movilidad pendular se caracteriza por la circularidad de movimientos que involucran distintos espacios de vida como el trabajo y el hogar, sin alterar el lugar de residencia del trabajador. Lobo, Cardoso, Almeida \& García (2017) son más específicos y la describen como un tipo de movilidad que desarrollan las personas respecto a diversas unidades espaciales que involucran viajes de corta distancia entre diferentes puntos. A partir del clásico patrón de movilidad pendular casa-trabajo, Niedzieliski \& Boschmann (2014) contrastaron la accesibilidad monótona -entendida como las posibilidades de acceso desarrolladas de manera rutinaria- y la accesibilidad no monótona - entendida como experiencias inesperadas en la movilidad - con la finalidad de investigar la movilidad pendular, lo que dio por resultado el desarrollo de procesos altamente significativos de exclusión socioespacial. Para los autores, las distancias que cubren cotidianamente los trabajadores pobres de Denver (Estados Unidos) suelen contener desplazamientos inesperados y adyacentes, ello genera diversos acontecimientos en la movilidad pendular y que no son necesariamente esperados, lo que da cuenta de la contingencia de la movilidad. 
En segundo lugar, la conmutación se define como el desplazamiento diario que realizan las personas con el objetivo de acudir al lugar de trabajo. Esta actividad conlleva generar diversas transformaciones en la vida cotidiana, tanto a nivel subjetivo (emociones, experiencias y sentimientos) como objetivos (desde la infraestructura de la movilidad), lo cual es influenciado por los cambios en el mundo del trabajo durante el presente siglo (Delclos \& Miralles-Guasch, 2017). Así, la conmutación emerge como una práctica fundamental para aquellos que viven distantes de los espacios productivos frecuentados diariamente. Las causas del incremento de la conmutación durante los últimos años están supeditadas a múltiples fenómenos sociales como la reestructuración de las ciudades, segregación residencial o procesos de suburbanización (Litman, 2016). En tercer lugar, los traslados de larga distancia constituyen la antítesis de los viajes de proximidad, y emergen de los procesos de dispersión urbana que generan una mayor necesidad de desplazamientos (Mateu, Seguí, \& Ruiz, 2017). Los traslados de larga distancia se relacionan directamente con la separación entre los espacios de concurrencia habitual y su nexo con redes e infraestructura de transporte que viene a suplir la demanda por conectividad. En este sentido, para Jiménez, Hidalgo, Campesino \& Alvarado (2018) un factor determinante está dado por la supremacía de modelos urbanos dispersos que traen como consecuencia la expansión de lo urbano por ocupación de lo rural, lo cual evidencia procesos de conurbanización y metropolización.

Aunque cada uno de los tres conceptos descritos aporta en la comprensión de la movilidad, ya sea como enfoque u objeto de investigación, los contrastes entre estos están dados por el vínculo adquirido con el territorio observado. De este modo, tanto la pendularidad como los traslados de larga distancia se posicionan en los extremos espaciotemporales de la movilidad, mientras que la conmutación intrarregional se vincula con aspectos de la territorialidad, más allá del espacio-tiempo considerado en la práctica de movilidad, y sin dejar de ser un factor relevante.

La conmutación desde las experiencias de movilidad. Las formas y consecuencias de la conmutación están íntimamente ligadas al territorio habitado y su relación con las prácticas cotidianas de movilidad. Al respecto, Soder $\&$ Peer (2018) plantean que en las zonas rurales del mundo la movilidad, la inclusión y las oportunidades de empleo pueden disminuir considerablemente si no se cuenta con una infraestructura de la movilidad acorde a las necesidades de la población. En este sentido, el transporte adquiere un rol fundamental en las experiencias de conmutación, lo cual es reafirmado por Keyes \& Crawford-Brown
(2018) en un estudio efectuado en Inglaterra que tuvo por objetivo conocer las variables que influyen en el modo de conmutación. Los autores concluyen que las personas con altos ingresos tienen mayores posibilidades de elegir el dispositivo de transporte para viajar al trabajo, lo cual permite reabrir el debate en torno a la emergencia de desigualdades sociales desde la perspectiva de la movilidad. Resulta particularmente relevante observar cómo las ciencias sociales se han interesado por definir y explorar, desde el paradigma de la movilidad, las transformaciones en el mundo del trabajo (Cui, Boisjolyb, El-Geneidyc \& Levinson, 2019). Para Dorow, Roseman \& Cresswell (2017) esta bifurcación hacia los estudios del trabajo desde la movilidad, permite plantear cinco ejes de investigación, a saber: articulación entre migración y movilidad por trabajo; relaciones de poder en el viaje al trabajo; afectividad en los movimientos por motivos laborales; movilidades y trabajo en el desarrollo de la vida cotidiana, y comovilidades de cosas, trabajadores e ideas. Estos cincos tópicos reflexionan respecto a la producción del conocimiento en sociedades que tienden a poner en el centro de la vida cotidiana la categoría trabajo y su poder para normar y propagar tipologías de interacción social.

Las redes y flujos laborales forman un eje central en la caracterización de las experiencias de movilidad de la población, lo que da cuenta del giro espaciotemporal de la sociedad en temáticas vinculadas a la desigualdad en aspectos del trabajo y su relación con otras esferas de la vida cotidiana. Como ejemplo de ello, Jirón \& Imilán (2015) plantean que la flexibilidad laboral influye considerablemente en la vida cotidiana de la población, lo cual promueve cambios en las formas de movilidad a partir del trabajo precario. En efecto, la resonancia del trabajo en la vida social está íntimamente ligada al desarrollo de movilidades, sobre todo en sociedades donde existe una fragmentación en los sentidos de pertenencia que conllevan situaciones de inestabilidad e incertidumbre (Bauman, 2003).

A nivel mundial, diversas pesquisas han centrado sus análisis en las dinámicas de conmutación y su relación con los estilos de vida de la población, tornándose reflejo de las asimetrías socioeconómicas y las transformaciones del paisaje (Bole, 2004; Garretón, 2012). En este sentido, la multiplicidad de factores que inciden en los desplazamientos al lugar de trabajo confiere un papel central a la experiencia de movilidad en concordancia con la infraestructura de la movilidad a disposición, lo cual abre el debate respecto a los espacios objetivos y subjetivos de la movilidad desde los procesos socioterritoriales y el espacio habitado (Espinoza, 2013). 
Al seguir a Santos (2017), aspectos sociodemográficos influyen en las diferentes formas de movilidad que adopta la población desde el ordenamiento territorial y la organización espacial, lo que muchas veces provoca desigualdades sociales desde la movilidad entre quienes cuentan con medios socioeconómicos para hacer de la movilidad algo factible de realizar y quienes no cuentan con los recursos necesarios (Cebollada, 2009), lo que promueve movilidades diferenciadas para acceder a personas, actividades y lugares.

Por lo antes mencionado, cobran relevancia las investigaciones que plantean conocer las actitudes de los trabajadores respecto a sus estilos de vida móviles. En el estudio de Jones \& Southcott (2015), los mineros de Yukon (Canadá) no demuestran mayores preocupaciones por el viaje, más bien, las recomendaciones de los autores están dadas por las vicisitudes en la contratación de personal local o externo, lo que provoca transformaciones en la vida cotidiana de los lugareños que viajan cortas distancias diariamente a las locaciones donde se instalan de manera estacionaria las empresas.

Desde la experiencia de los conmuters (conmutantes), resaltan investigaciones que se centran en la calidad del viaje de los trabajadores, donde factores como la ubicación residencial, modo de viaje y el dispositivo de transporte influyen considerablemente en un mayor o menor bienestar (Handy \& Thigpen, 2019). De igual modo, existe una correlación significativa entre la práctica de desplazamiento y la aparición de trastornos psicológicos en los conmuters, tornándose una problemática de interés sociopolítico fundamental en los tiempos actuales (Giménez \& Molina, 2019).

Asimismo, la conmutación permite prestar atención a diversas esferas de la vida social, enfocándose en variados fenómenos de la sociedad contemporánea, donde pareciera que lo moderno está íntimamente relacionado con el sujeto que se desplaza (Salazar en Bordonaro, 2018). Ejemplo de ello son las transformaciones que experimentan los conmuters en sus condiciones de salud, lo cual permite conocer ámbitos que se ven afectados por sus estilos de vida. Al respecto, destacan estudios que enfatizan en aspectos como la movilidad y su afección negativa en la salud del trabajador y su familia (Newhook et al., 2011); los efectos nocivos de la contaminación en mujeres embarazadas que se desplazan cotidianamente por motivos laborales (Blanchard, Deguen, \& Kihal, 2018), y los estilos alimenticios desfavorables para aquellos trabajadores que pasan largo tiempo de la jornada diaria fuera de casa (Shareck, Frohilich \& Kestens, 2014).
Tal como se ha explicado, resulta relevante observar el desarrollo de la movilidad en su ambiente, al integrar las interacciones sociales y lo escenarios móviles en el análisis (Ingold, 2012). En este ámbito, diversos trabajos se han interesado por las experiencias de las personas en movimiento, que indagan en las subjetividades desde el paradigma de la movilidad (Cresswell, 2006; Sheller, 2014; Sheller \& Urry, 2016).

La conmutación y sus diversos ejes de comprensión en Chile. En el marco de la comprensión de los niveles y objetos de estudio de las ciudades, nos interesa sobre todo la ciudad intermedia desde la vacancia propia de sus estudios, donde "es necesario profundizar en estos sistemas urbanos a partir de la experiencia de sus habitantes para comprender adecuadamente la diversidad y complejidad de procesos que las ciudades experimentan desde su carácter de lugares emplazados, y así poder aportar a una planificación urbana más inclusiva y sustentable" (Salazar et al., 2018, p. 110). Esta perspectiva entrega múltiples campos de acción en la comprensión de la movilidad desde los sentidos, la representación del espacio habitado y las rutinas cotidianas de movilidad que ocurren en ciudades intermedias, menores y pequeñas tan características de nuestro país.

Maturana \& Rojas (2015), basándose en la División de Desarrollo Urbano, plantea la existencia de "cuatro rangos para definir tipos de ciudades: Ciudades metropolitanas, con una población mayor a 300.000 habitantes, Intermedias Mayores, entre 100.000 a 300.000, Intermedias Menores entre 20.000 a 99.999 y Pequeñas Ciudades con una población entre 5.000 y menor a 20.000 " (p. 29). Asimismo, argumenta que, para el caso chileno, junto con aspectos vinculados a la cantidad de población, se deben considerar otros aspectos como: el rol en la administración políticoadministrativa; poseer servicios especializados; poseer saldos positivos en el proceso de migración; tasa de crecimiento para el período 1982-2002 igual o superior al promedio; contar con población igual o mayor al promedio de los habitantes de cada capital provincial, y presentar un total de llegadas a establecimientos de alojamiento turístico igual o sobre el promedio nacional (Maturana \& Rojas, 2015).

Estas definiciones nos permiten examinar cómo la conmutación es diferente en función de las características propias de las ciudades. Las diversas escalas de ciudades hacen que el tratamiento de estas se relacione directamente con los cambios sociodemográficos y territoriales que experimentan los territorios. De esta manera, según Maturana \& Rojas (2015), las dinámicas sociales de 
conmutación están imbricadas con el tamaño de las ciudades, donde las ciudades intermedias menores y ciudades menores tienden a depender de las de mayor rango para su desarrollo social y económico.

En efecto, observamos que el estudio de la conmutación (desplazamientos cotidianos de personas que viven y trabajan en ciudades distintas) es reciente en nuestro país, e incluye escasos trabajos desarrollados al alero de la movilidad como enfoque u objeto de investigación, destacándose, por un lado, estudios que profundizan aspectos de la conmutación en grandes ciudades (conmutación intrametropolitana) a partir de su poder de expansión $\mathrm{y}$, por otro lado, emerge la conmutación intrarregional, entendida desde los desplazamientos que se provocan entre el hogar y el lugar de trabajo en relación con ciudades intermedias y menores.

En Chile, y desde una perspectiva que propone examinar el trabajo agrario y la ruralidad a partir de la movilidad cotidiana, Canales, Canales y Hernández (2018) analizan la conmutación de corta distancia entre comunas agrupadas y no metropolitanas. Para los autores, la conmutación es entendida como "el desplazamiento cotidiano del trabajador entre una localidad de hábitat y una localidad de trabajo y empleo" (Canales et al., 2018, p. 6). De este modo, la movilidad laboral organiza los territorios agrarios a partir de la transformación experimentada en la relación campo-ciudad producto de la modernización de agro chileno en el último tiempo.

Si se sigue a Canales \& Canales (2016), los desplazamientos de conmutación se agruparían en intrametropolitanos, interregionales e intrarregionales. La primera categoría consideraría lo acontecido en la capital nacional, mientras que la movilidad interregional estaría determinada por movimientos de larga distancia entre las diferentes regiones, tratándose muchas veces de desplazamientos asociados, por ejemplo, a la gran minería.

Asimismo, estos autores plantean una movilidad intrarregional, la cual se desarrolla específicamente en territorios agrarios. El aporte de esta categoría se sustenta en que "se establece en los territorios agrarios un sistema de relacionamiento pluricentrado que integra lo urbano y lo rural, el campo y sus ciudades" (Canales \& Canales, 2016, p. 1). Esta perspectiva permite observar cómo las distancias entre lo urbano y lo rural tienden a disociarse a partir de las prácticas y las experiencias de desplazamientos cotidianos.

En efecto, pareciera que, al plantear causas sociológicas y económicas de la conmutación latinoamericana, se encuentra el predominio del agronegocio, entendido como modelo que promueve las actividades empresariales productivas y comerciales desarrolladas en el campo. Para Venturini \& Castro (2018), este modelo ha transformado los patrones de movilidad de los trabajadores agrarios latinoamericanos, quienes, por funciones laborales específicas, migran temporariamente debido a la demanda de mano de obra. Aunque existe una robusta producción académica centrada en el análisis del trabajo precario y las reconfiguraciones territoriales de la población rural (Trpin \& Rodríguez, 2015; Valdés S., Godoy R. \& Mendoza A., 2017), predomina aún una vacancia en el ámbito académico local respecto a investigaciones que profundicen en las prácticas y experiencias de movilidad de este segmento de personas que construyen sus espacios de vida entre lo urbano y lo rural.

Como ya señalamos, las movilidades por motivos de trabajo en la ruralidad y en la ciudades intermedias y pequeñas han sido escasamente abordadas, a pesar de que son sumamente relevantes para aquellos habitantes que viven en lugares más periféricos del desarrollo económico social. En estos territorios emergen dispositivos de transporte como bicicletas, lanchas, buses interurbanos y ferrocarriles que funcionan como nexo en la conectividad con el lugar de trabajo (Lazo \& Carvajal, 2017, 2018; Riquelme \& Lazo, 2019). Es en la movilidad intrarregional donde la experiencia de los habitantes o conmuters se propaga a partir de complejas redes de accesibilidad, lo que agudiza la "espesura" de la movilidad (Jirón \& Mancilla, 2013), y provoca pesados y dificultosos desplazamientos para quienes habitan estos territorios. Así, emergen barreras en las prácticas de movilidad desde la planificación urbana, e irrumpen estrategias y tácticas planteadas por ellos para acceder a los lugares de frecuentación.

\section{Metodología del estudio}

Las ciudades intermedias menores: La Unión y Río Bueno. Lo aquí presentado se basa en una investigación mayor que involucró seis comunas durante la fase de trabajo de campo $^{1}$. Las comunas seleccionadas para este artículo (La Unión y Río Bueno) a pesar de pertenecer a la Región de

${ }^{1}$ Proyecto Fondecyt de iniciación 11171028. Cabe señalar que la cantidad de participantes sombreados (veinte) sobrepasa los aquí presentados (tres), pero por motivos vinculados a los objetivos de este manuscrito se privilegiará las experiencias de movilidad de solo tres habitantes de las comunas de La Unión y Río Bueno. Asimismo, se debe tener en cuenta que esta investigación persigue un objetivo de mayor extensión relacionado con el proyecto marco de esta investigación donde se busca analizar las prácticas y experiencias de movilidad en las ciudades intermedias del sur de Chile. 


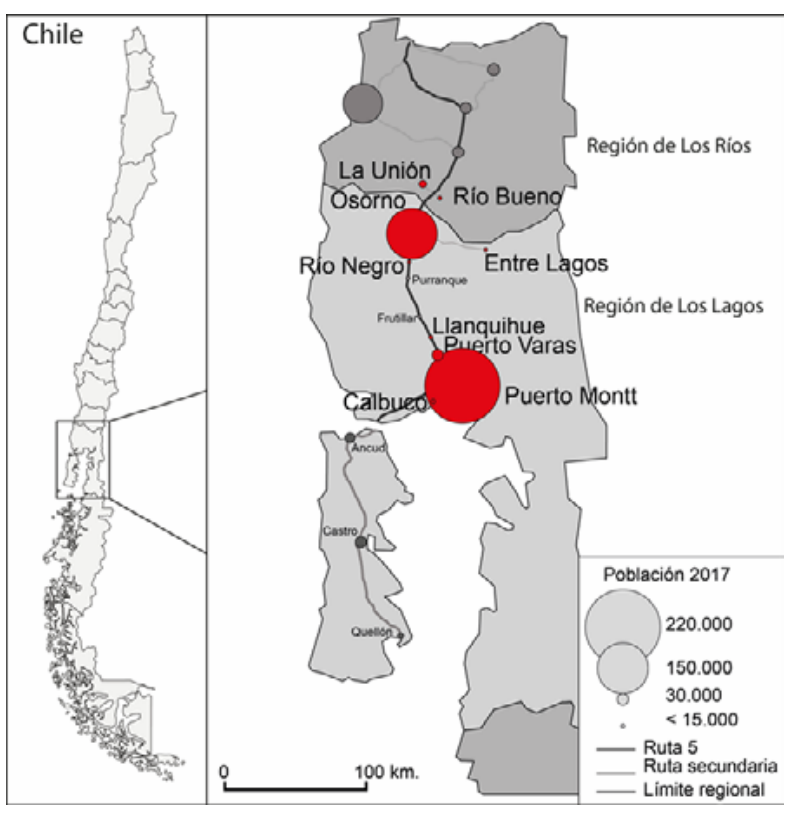

Figura 1. Mapa de la Región de Los Lagos y Los Ríos con las ciudades estudiadas. Fuente: Elaboración propia.

Los Ríos poseen una eminente dependencia con la ciudad de Osorno, capital de la Provincia de Osorno, región de Los Lagos (Figura 1). Esta dependencia está íntimamente relacionada con las experiencias de movilidad de los conmutantes que cotidianamente desarrollan sus rutinas de desplazamiento con el objetivo de acudir a la capital regional por motivos de trabajo. Dentro de las comunas seleccionadas, existen ciertos vínculos y disociaciones a partir de aspectos territoriales, experiencias de viaje, infraestructura de la movilidad y cuestiones de carácter afectivo.

Las ciudades seleccionadas (La Unión y Río Bueno) corresponden a ciudades intermedias menores y tienen entre 38.036 habitantes y 31.702 habhabitantes, respectivamente. El número de personas que viaja diariamente a la ciudad de Osorno por trabajo y estudio supera las 1.480 en La Unión y las 1.038 en Río Bueno según el último Censo del año 2012, pero se estima que esta cifra ha ido en aumento (Figura 2).

Acompañar a las personas en sus desplazamientos. En el marco de la producción académica vinculada a enfoques cualitativos que centran los análisis en las experiencias y percepciones de las personas, en esta investigación se desarrollaron "etnografías de sombreo" (Jirón, 2010). En efecto, los sombreos permiten acompañar a las personas en sus desplazamientos diarios, es decir, se trata de un "enfoque etnográfico multisituado en movimiento, que permite describir las experiencias de movilidad" (Imilán, Jirón \& Iturra, 2015, p. 93). Estos sombreos fueron desarrollados durante el período 2018-2019 en seis comunas de la Región de Los Lagos y Los Ríos, respectivamente
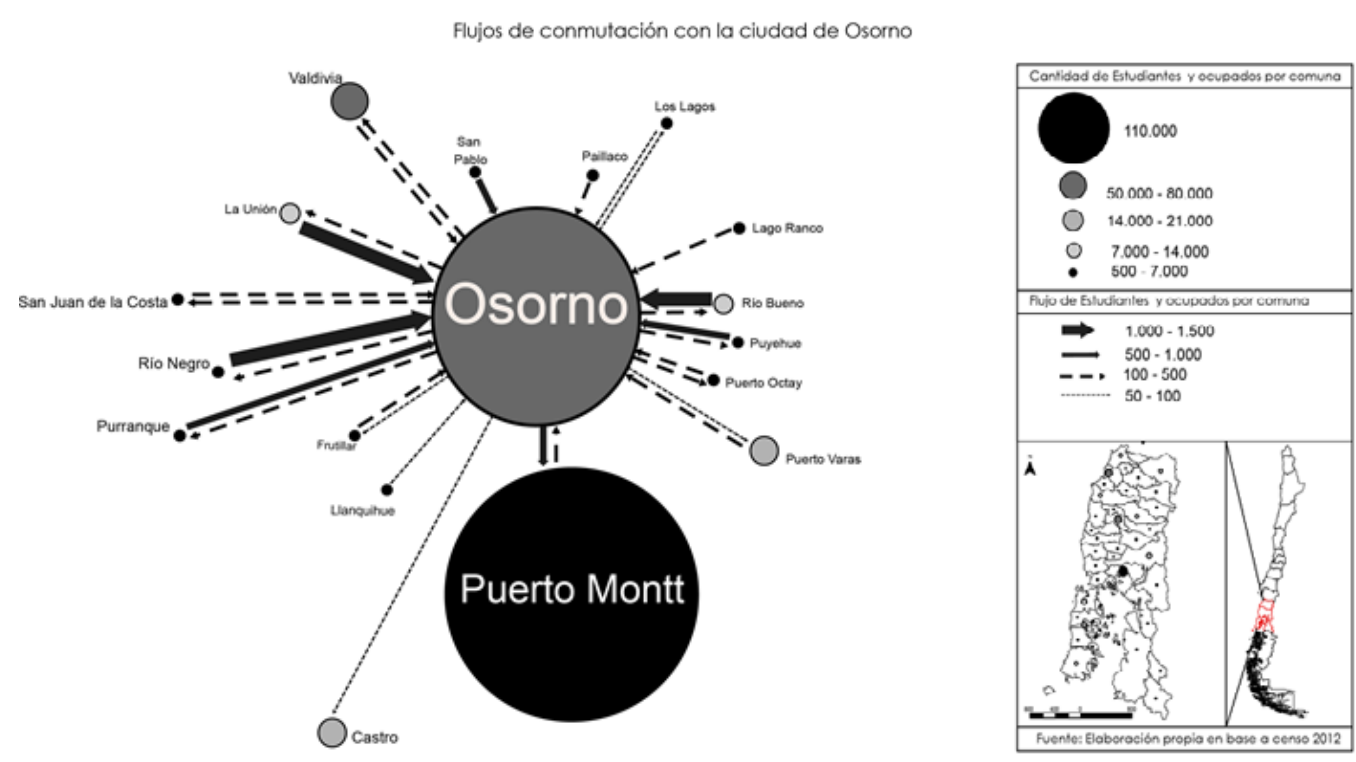

Figura 2. Mapa de la Región de Los Lagos y Los Ríos con las ciudades estudiadas. Fuente: Elaboración propia. 
Tabla 1

Matriz de síntesis.

\begin{tabular}{|c|c|c|c|c|c|c|}
\hline Ciudades & Puyehue & La Unión & Río Bueno & Río Negro & Llanquihue & Puerto Varas \\
\hline Coordenadas & $\begin{array}{l}\text { Lat } 40^{\circ} 40^{\prime} 0^{\prime \prime} \mathrm{S}, \\
\text { Log } 72^{\circ} 37^{\prime} 0^{\prime \prime} \mathrm{W}\end{array}$ & $\begin{array}{l}\text { Lat } 40^{\circ} 17^{\prime} 0^{\prime \prime} \mathrm{S}, \\
\text { Log } 73^{\circ} 5^{\prime} 0^{\prime \prime} \mathrm{W}\end{array}$ & $\begin{array}{l}\text { Lat } 40^{\circ} 19^{\prime} 0^{\prime \prime} \mathrm{S}, \\
\text { Log } 72^{\circ} 58^{\prime} 0^{\prime \prime} \mathrm{W}\end{array}$ & $\begin{array}{l}\text { Lat } 40^{\circ} 47^{\prime} 46.14^{\prime \prime} \mathrm{S} \\
\text { Log } 73^{\circ} 12^{\prime} 58.1^{\prime \prime} \mathrm{W}\end{array}$ & $\begin{array}{l}\text { Lat } \\
41^{\circ} 15^{\prime} 0^{\prime \prime} \mathrm{S} \\
\log 73^{\circ} 1^{\prime} 0^{\prime \prime} \mathrm{W}\end{array}$ & $\begin{array}{l}\text { Lat } 41^{\circ} 19^{\prime} 0^{\prime \prime} \mathrm{S}, \\
\text { Log } 72^{\circ} 59^{\prime} 0^{\prime \prime} \mathrm{W}\end{array}$ \\
\hline $\begin{array}{l}\text { Contexto } \\
\text { territorial }\end{array}$ & Rural e intercultural & Urbano-rural & Urbano-rural & Urbano-rural & Urbano-rural & $\begin{array}{l}\text { Urbano, ciudad } \\
\text { intermedia, turística }\end{array}$ \\
\hline $\begin{array}{l}\text { Medios de } \\
\text { transporte y } \\
\text { tecnología }\end{array}$ & $\begin{array}{l}\text { Buses o microbuses, } \\
\text { A pie y motorizado } \\
\text { Menor uso de celular }\end{array}$ & $\begin{array}{l}\text { Microbuses, bicicleta, } \\
\text { transporte privado. } \\
\text { Celular, videojuegos, } \\
\text { música mp3 }\end{array}$ & $\begin{array}{l}\text { Buses pequeños } \\
\text { Uso del celular } \\
\text { videojuegos, música } \\
\text { mp3. }\end{array}$ & $\begin{array}{l}\text { Buses pequeños } \\
\text { Uso del celular } \\
\text { videojuegos, música } \\
\text { mp3. }\end{array}$ & $\begin{array}{l}\text { Micros pequeñas, viajes } \\
\text { más cortos } \\
\text { Uso del celular }\end{array}$ & $\begin{array}{l}\text { Diversidad de buses } \\
\text { Alto uso del automóvil } \\
\text { Uso del celular }\end{array}$ \\
\hline $\begin{array}{l}\text { La } \\
\text { experiencia } \\
\text { de viaje }\end{array}$ & $\begin{array}{l}\text { Memoria e historia. } \\
\text { Viajes con sentido. } \\
\text { Experiencia de esfuerzo, } \\
\text { Valoración del lugar } \\
\text { propio. }\end{array}$ & $\begin{array}{l}\text { Tiempo de descanso v/s } \\
\text { agotamiento. } \\
\text { Familiaridad } \\
\text { Organización } \\
\text { Técnicas y maniobras } \\
\text { Usos } \\
\text { Valoración del lugar } \\
\text { propio }\end{array}$ & $\begin{array}{l}\text { Tiempo de descanso v/s } \\
\text { agotamiento } \\
\text { Familiaridad } \\
\text { Ritualización } \\
\text { Organización } \\
\text { Técnicas y maniobras } \\
\text { Usos } \\
\text { Valoración del lugar } \\
\text { propio }\end{array}$ & $\begin{array}{l}\text { Tiempo de descanso } \\
\text { v/s agotamiento de un } \\
\text { viaje a pie } \\
\text { Familiaridad } \\
\text { Ritualización } \\
\text { Organización } \\
\text { Técnicas y maniobras } \\
\text { Usos } \\
\text { Valoración del lugar } \\
\text { propio }\end{array}$ & $\begin{array}{l}\text { Valoración del lugar } \\
\text { Menor reconocimiento } \\
\text { del otro } \\
\text { Organización } \\
\text { Conexión con Pto. Montt } \\
\text { (por bus y carretera) }\end{array}$ & $\begin{array}{l}\text { Movilidad privilegiada } \\
\text { por la conexión con } \\
\text { Pto. Montt (por bus y } \\
\text { carretera) } \\
\text { Organización } \\
\text { Menor reconocimiento } \\
\text { del otro } \\
\text { Valoración del lugar } \\
\text { (elementos paisajisticos) }\end{array}$ \\
\hline $\begin{array}{l}\text { Lo } \\
\text { Relacional y } \\
\text { Afectivo }\end{array}$ & $\begin{array}{l}\text { Conocimiento del } \\
\text { territorio, de la } \\
\text { naturaleza, de las rutas } \\
\text { (a pie y en medios } \\
\text { motorizados) } \\
\text { Objetos propios v/s } \\
\text { modernidad }\end{array}$ & $\begin{array}{l}\text { Cuerpo relajado y activo } \\
\text { Conocimiento de los } \\
\text { medios de transporte, la } \\
\text { ruta (certeza y confianza) }\end{array}$ & $\begin{array}{l}\text { Cuerpo relajado y activo } \\
\text { Conocimiento de los } \\
\text { medios de transporte, la } \\
\text { ruta (certeza y confianza) }\end{array}$ & $\begin{array}{l}\text { Cuerpo relajado y activo } \\
\text { Conocimiento los medios } \\
\text { de transporte, la ruta } \\
\text { (certeza y confianza) }\end{array}$ & $\begin{array}{l}\text { Cuerpo relajado y activo } \\
\text { Conocimiento los medios } \\
\text { de transporte, la ruta } \\
\text { (certeza y confianza) }\end{array}$ & $\begin{array}{l}\text { Cuerpo apurado, más } \\
\text { urbano y móvil } \\
\text { Conocimiento más } \\
\text { práctico del "otro". }\end{array}$ \\
\hline
\end{tabular}

Fuente: Elaboración propia

(Puyehue, La Unión, Río Bueno, Puerto Varas, Llanquihue y Río Negro), no obstante, se seleccionaron, tal como se mencionó anteriormente, solo tres casos pertenecientes a las ciudades de Río Bueno y La Unión. La elección de las tres comunas nace a partir del análisis del censo del año 2002 y 2012, donde estas ciudades aparecían, junto a otras de la Región de Los Ríos y Los Lagos, como muy dependientes de la ciudad de Osorno y Puerto Montt, en lo que respecta a los trayectos cotidianos por motivos de trabajo y estudio. Este fenómeno propicia un relevante campo de investigación respecto a las condiciones de vida desde los habitantes de estas ciudades, donde no siempre el lugar de trabajo se encuentra en la comuna de residencia. Dentro de los criterios para la selección de los participantes, se privilegió a personas que viajarán a trabajar a una comuna distinta de la que residían, utilizaban transporte privado y/o público para sus desplazamientos diarios y llevaban más de un año desarrollando la misma rutina de desplazamiento.

El acompañamiento o sombreo, en tiempo real y durante los viajes, permitió conocer y descubrir cómo se construía el viaje, lo que posibilitó la intromisión del investigador en espacios íntimos como la casa o el lugar de trabajo, y en sitios de acceso público como calles, microbuses, terminales, plazas o paraderos. Todos estos lugares dan cuenta de la movilidad como una actividad que trasciende el tiempo-espacio de viaje en sí. Por consiguiente, el sombreo requirió de más de un solo encuentro con los participantes sombreados, ya que hubo reuniones de acercamiento previo donde se estableció confianza y se planteó una entrevista exploratoria; posteriormente se realizó el sombreo y, finalmente, en algunos casos, se volvió a desarrollar una entrevista con el objetivo de recabar información necesaria que surgió luego del viaje.

Matriz de sintesis de la movilidad ${ }^{2}$. Para analizar la información recolectada se realizó una matriz de doble entrada. En ella se identificaron, por un lado, los tópicos relacionados con la movilidad cotidiana (contexto territorial, medios de transporte/tecnologías, experiencia y lo relacional/ afectivo) y, por el otro, se señalan las ciudades estudiadas. Lo anterior permitió caracterizar las movilidades de cada ciudad, tal como se muestra en la Tabla 1.

En rigor, las experiencias de viaje responden a modos de vida asociados estrechamente con aspectos territoriales, lo cual revitaliza aspectos culturales en el desarrollo afectivo de la movilidad. Las divergencias entre Puyehue y Puerto Varas, por nombrar algunas de las comunas estudiadas, permiten considerar aspectos espaciotemporales en el desarrollo de la movilidad, las cuales están íntimamente

${ }^{2}$ La matriz de síntesis exhibe toda la información recolectada en el marco de la investigación que sustenta este escrito. 
relacionadas con la vida cotidiana que los habitantes de estos lugares experimentan. Mientras Puyehue ejemplifica elementos rítmicos y socioculturales de una ruralidad intercultural, Puerto Varas exhibe entre sus conmutantes, necesidades y experiencias vinculadas al desarrollo de experiencias de ciudades en expansión y con un eminente componente de comodidad, amenidad y turismo.

\section{Acompañando a los sujetos en sus viajes}

A continuación, se presentan tres sombreos de habitantes de La Unión (2) y Río Bueno (1) que, por motivos laborales, viajan cotidianamente a la ciudad de Osorno. Estos acompañamientos tuvieron como objetivo conocer tanto las dimensiones objetivas, como subjetivas, asociadas al viaje cotidiano.

"Viajar en automóvil me da comodidad y mayor control". Francisco tiene veintiocho años, es soltero y en la actualidad vive en la ciudad de La Unión junto a su hermana y la pareja de ella. La Unión es una pequeña ciudad que sirve como capital de la provincia de Ranco, Región de Los Ríos. Francisco trabaja como profesor de Matemáticas en un colegio del centro de la ciudad de Osorno. Viaja, desde hace un año, de lunes a viernes desde La Unión a Osorno en su vehículo particular (Figura 3).

Francisco se levanta temprano, a eso de las cinco de la mañana. Le gusta levantarse con tiempo para organizar las clases a primera hora y evitar los atochamientos vehiculares que se producen a esa hora de la mañana en la carretera. Para él, la rutina de viaje ha cambiado con los años, tiempo en el que logró adquirir ciertas habilidades para sortear barreras como caminos en mal estado o largas filas de vehículos que avanzan lentamente. Estas habilidades están dadas por el conocimiento de los caminos y lugares que constituyen la ruta de viaje, lo cual le entrega sentimientos de seguridad ante posibles eventos que puedan retrasar sus viajes. Llegamos a su casa a eso de las 06:51 a.m., para acompañarlo hasta Osorno. Nos ve y se acerca rápidamente al auto y deja sus cosas esparcidas en el asiento trasero. Mientras nos saludamos, Francisco me comenta las actividades que tiene contempladas para el día de hoy, sobre todo aquellas relacionadas con el viaje de regreso, donde incluirá a su familia. Para él, viajar al trabajo es una actividad bien percibida producto del automóvil que le permite desplazarse.

Nos acomodamos y ponemos cinturón. Lo primero que ha hecho Francisco después de encender el auto es prender la radio, conectada a un pendrive que suele preparar con música los domingos para los viajes de toda la semana.
Maneja muy rápido y la salida es expedita de la ciudad. A las 07:00 a.m. ya estamos en el cruce, para tomar la ruta 5. Se ve a esa hora un número importante de vehículos en la carretera. El paisaje aún es sombrío, con algo de neblina y oscuridad por la hora. Francisco maneja a $110-120 \mathrm{~km} / \mathrm{h}$, adelanta sin mucha complicación buses y camiones.

Francisco me comenta que siempre ha tratado de evitar los viajes en bus, pues desde pequeño le producían mareos e incomodidad. Además, está acostumbrado a viajar con muchas cosas de su trabajo, y en caso de tomar bus tendría que ir hasta la terminal de buses de La Unión para alcanzar algún asiento, ya que prefiere viajar sentado en transporte público. Para Francisco, el automóvil se torna un medio de transporte fundamental en sus actividades cotidianas, ya que el tiempo de viaje entre su lugar de residencia y el trabajo es optimizado con la utilización del vehículo particular. Aunque reconoce que fue una inversión económica importante, la comodidad y autonomía que entrega viajar en automóvil es impagable.

Siendo las 07:15 a.m. ya estamos en el peaje de Osorno. Francisco llega hasta aquí con una leve sonrisa, ya que sabe que al no haber atochamientos puede circular con mayor relajo, a diferencia de otros días donde se generan enormes filas de automóviles que implican un atraso en su hora de arribo. Ya estamos en Osorno, y al llegar al punto en que la calle Mackenna se bifurca en Mackenna Norte y Lynch, hay una patrulla de carabineros que indica el cambio de sentido de una de las vías para facilitar el gran tránsito oeste-este que se avecina en la ciudad.

Seguimos por calle Lynch, también semivacía, hasta calle Prat. Aqui es donde complica, comenta Francisco, con una incomodidad evidente en su rostro que refleja la pérdida de control sobre los tiempos de viaje. En la entrada por calle Julio Buschman es donde se encuentra con los tacos matinales, al menos un día a la semana, comenta Francisco. Si hay un carabinero dirigiendo el tránsito es peor, dice. Pero hoy Prat no está atochada, aunque sí hay bastantes autos, paraderos con harta gente y micros que vemos pasar llenas de pasajeros por calle Bilbao.

Son las 07: 25 a.m., conversamos un poco en el auto antes de bajarnos para que Francisco comience su jornada laboral. Francisco insiste en la relevancia del automóvil en su vida cotidiana, cree que los automovilistas que viajan largas distancias diariamente están sometidos a un fuerte cansancio y estrés. Se dispone a sacar sus cosas desde el asiento de atrás, mientras busca las llaves del auto para cerrar, con bolsas en ambas manos y la mochila a la espalda. Ninguno de esos tres complementos se ve 

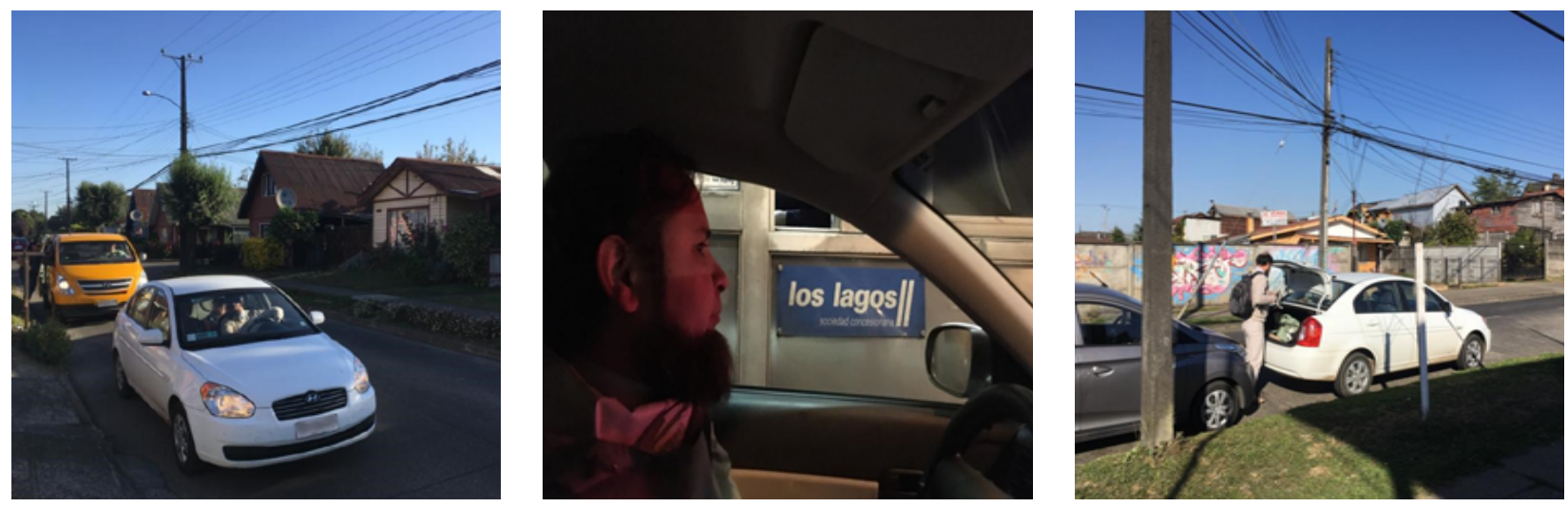

Figura 3. Secuencia del viaje de Francisco en su automóvil. Fuente: Colección personal.

liviano. En el primero lleva su almuerzo, en el segundo las carpetas con todo el material para cada curso, mientras que en la mochila lleva su computador. Nos despedimos para volver a reunirnos en la tarde, cuando emprendamos la vuelta a La Unión.

Francisco termina su jornada a las 17.15 p.m., hora pactada para nuestro reencuentro. Se le ve cansado, con su chaqueta al brazo, junto a sus bolsos y mochila. Me comenta que en la tarde ha tenido clase con un primero medio muy desordenado, que la sala era pequeña y que tampoco ha contribuido la alta temperatura del día.

Cruzamos la calle apenas observamos que no vienen autos, ahí es donde está estacionado su automóvil, nos subimos para emprender el viaje de regreso. En el trayecto inicial me recuerda que no será un día tan habitual de viaje. Pasaremos a buscar a sus padres y hermana cerca de la terminal. Su padre pasó la noche en la clínica por una operación menor, me explica, no ha pasado nada, pero hoy su madre y su hermana han venido a buscarlo y Francisco los llevará de vuelta a La Unión.

Luego de unos minutos de viaje, nos encontramos en la calle Mackenna, y es ahí donde Francisco se detiene brevemente para que su familia pueda subir al automóvil. Madre, padre y hermana ya están dentro de vehículo, en la parte posterior. Así, los cinco ya instalados en el auto seguimos camino a La Unión. La entrada a la carretera se hace con precaución, vienen autos desde el sur reduciendo velocidad y otros como nosotros (y los que vienen detrás) tratan de incorporarse a una fila que debe seguir la única pista habilitada por los trabajos de mantención. Pasados los 800 metros de conos que dividen la ruta en dos, nos relajamos un tanto y dejamos de prestar tanta atención al resto de los autos.

Francisco comenta que entre vivir en Osorno y vivir en La Unión, prefiere La Unión, pues la diferencia en tiempo de viaje (unos cuarenta y cinco minutos) sería mínima. También razones como la seguridad de la ciudad y el precio de la vivienda influyen en su decisión. Luego de un viaje tranquilo, donde nuestro silencio como viajeros es exacerbado por el volumen de la música, hemos llegado a La Unión. Ya en la casa de Francisco, antes de detener el auto, él le ha dicho a su padre que lo estacionará. Me bajo del automóvil y me despido de la familia, que se dispondrá a tomar once y compartir un momento de intimidad.

La experiencia de Francisco denota el deseo de fluidez. Esa inmediatez relacionada con el movimiento más allá del viaje en sí (Sheller \& Urry, 2016) adquiere múltiples significados en las actividades cotidianas. El automóvil, como dispositivo de transporte alcanzado con el afán de mejorar la calidad de vida, posiciona a Francisco como una persona que puede hacer de su movilidad una actividad factible de realizar en relación con su poder adquisitivo y su ciclo vital (Cebollada, 2009).

"Tomar micro es agotador, pero necesario para llegar a trabajar". Loreto, cuarenta y cinco años, es casada y tiene cuatro hijos. Junto a su familia, Loreto vive en villa Los Parques, comuna de La Unión. Loreto trabaja como ejecutiva en una caja de compensación en la ciudad de Osorno, capital de la provincia de Osorno, Región de Los Lagos. Loreto viaja de lunes a viernes a Osorno en los días laborales, es una rutina que ha debido organizar combinando diferentes dispositivos de transporte (Figura 4). En los días de semana, Loreto se levanta a las 06:30 


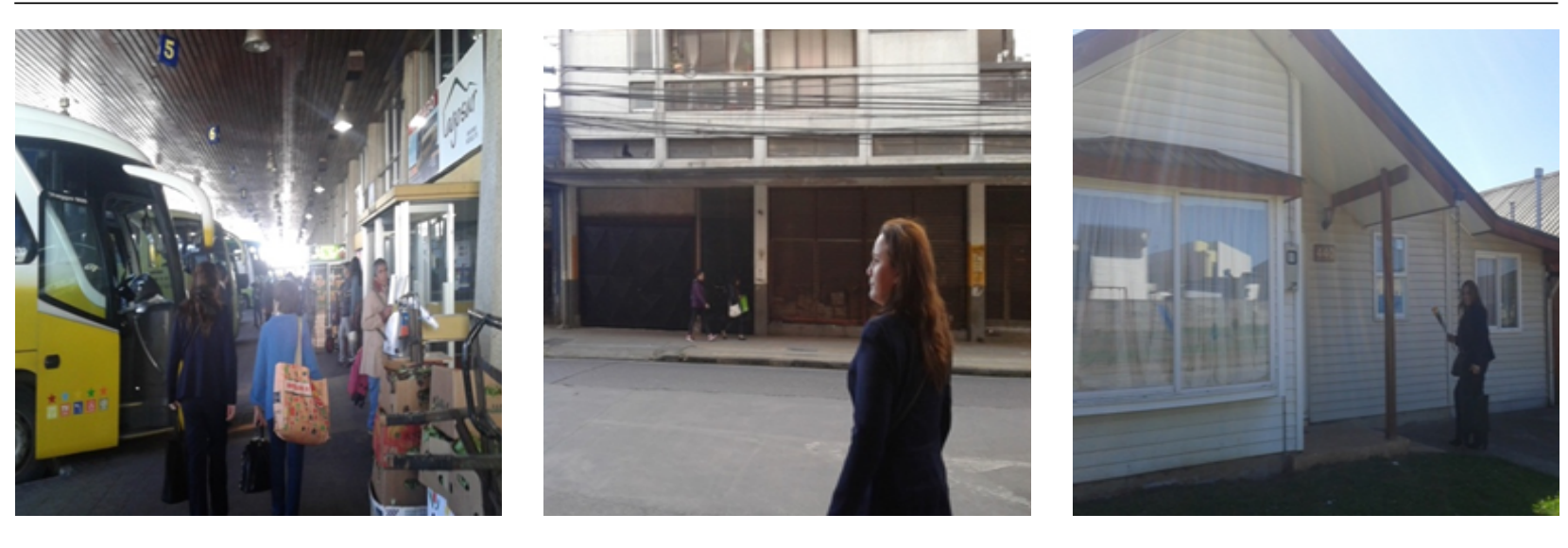

Figura 4. Secuencia del viaje de Loreto en microbús. Fuente: Colección personal.

a.m., tiempo que aprovecha para organizar las comidas de sus hijas, así como desarrollar su higiene personal. Nos reunimos a las 07:15 a.m. en su hogar. Al llegar me recibe afectuosamente, mientras aguardo tranquilamente que termine de hacer sus actividades matutinas orientadas al cuidado familiar, para así, posteriormente, disponer a desplazarnos hacia su lugar de trabajo.

Salimos de su casa a eso de las 07:30 a.m. Loreto ha llamado un taxi con el objetivo de que la acerque a la terminal de buses. El uso del taxi para Loreto no es permanente. Generalmente quien la acerca a la terminal es su marido o su hija, pero por ahora, al tener el vehículo en reparaciones, ha tenido que optar por el taxi. Caminar a la terminal le significaría al menos cuarenta minutos, y el uso de colectivos a esa hora es incierto, pues suelen pasar repletos.

El taxi llega a las 07:36 a.m., estacionándose frente a la casa. Loreto se pone la chaqueta y se despide muy afectuosamente de su hija. Se sienta en el asiento de copiloto y hace el trayecto en silencio. En las primeras cuadras paga $\$ 1.800$ por el viaje. El camino a la terminal de buses tarda menos de cinco minutos, bajando por el acceso principal a La Unión.

Ya en la terminal, Loreto me hace notar que el bus que ella suele tomar está estacionado. Por lo general, me ha comentado, ella llega antes que aparezca, esperándolo en el andén con los otros pasajeros. Loreto, se sube al bus rápido, saluda a algunos conocidos de viaje. El chofer, Ricardo, a quien Loreto conoce desde que viaja a Osorno por trabajo, hoy no está. Loreto saluda uno por uno, sonriendo, a quien reconoce. La tarifa oficial es $\$ 1.200$, no obstante, la mayoría de los pasajeros paga
\$1.000. El bus emprende el viaje a las 07:50 a.m., poco más de la mitad de los asientos van ocupados. El bus, mientras avanza en su ruta, ejecuta diversas paradas con el objetivo de incrementar la cantidad de pasajeros. Suben algunos conocidos de Loreto, con los cuales se saluda afectuosamente.

Mientras nos desplazamos, los viajeros realizan diversas actividades como leer, conversar, observar el paisaje y adelantar el trabajo administrativo (revisar documentos) son las acciones más recurrentes. Para Loreto, dormir se ha traducido en un actividad fundamental, sostiene: yo me subo al bus, le guardo puesto a una señora de edad que viaja con nosotros, que es la señora Mary, a lo mejor la conociste, espero que ella se suba y cuando ya vamos saliendo de La Unión, ella me pregunta ‘¿vas a dormir?', 'sí, le digo yo, 'tengo sueño', y ahi me quedo dormida hasta llegar. En el trayecto, Loreto, me comenta que en invierno no tienen calefacción, por lo que junto a sus carteras y bolsas lleva una manta para sus pies. Reconoce que es un bus espacioso en relación con otros, con mayor cantidad de asientos, aunque esto no implica que se encuentren ciertas incomodidades al llenarse en las mañanas.

El microbús llega a las 08:40 a.m. a la terminal de Osorno, momento en el que pagamos $\$ 1.000$, y Loreto junto a su compañera de viaje, María Eugenia, descienden y emprenden camino a sus respectivos lugares de trabajo. El día está frío, caminamos los tres algunas cuadras, momento para dejar a María Eugenia en su lugar de trabajo y seguir junto a Loreto a su lugar de trabajo. Estamos poco antes de las 09:00 a.m. en la oficina de Loreto, nos despedimos para volver a encontrarnos después de la jornada laboral. Loreto termina su jornada laboral los viernes a las 15:20 
p.m. Nos reunimos a la entrada de su lugar de trabajo. Se ve contenta y con la idea de pasar, como de costumbre, a comprar un par de encargos para su casa antes de tomar el bus de vuelta a La Unión. Caminamos dos cuadras por calle Matta, donde aumenta el número de peatones a medida que nos acercamos a la plaza de Armas. A diferencia de la mañana, Loreto no va apurada. Esperamos en los semáforos. Entramos a la galería por calle Mackenna a la librería del mismo nombre. A medida que nos aceramos a la terminal, Loreto habla de sus caminatas en soledad por la ciudad y la sensación de inseguridad que tiene al respecto, sostiene: acá en Osorno, de repente si te pillan sola por ahi te pueden asaltar, y siempre con ese temor. De hecho, la cartera que yo uso es cruzada.

A las 15:45 p.m. estamos en la terminal. Loreto toma ubicación en el andén, pues no ha llegado el próximo bus que saldrá a La Unión. En el andén se genera una pequeña aglomeración de gente. Loreto insiste en que esta es la parte de sus viajes cotidianos que menos le gusta. Hay alrededor de doce personas que se ubican desordenadamente alrededor de donde debería ubicarse la puerta del bus próximo a salir. Al subir, veo que Loreto tomó un asiento de ventana, reservándome el asiento del pasillo. De los poco más de cuarenta asientos del bus, aproximadamente quedan libres unos catorce. Loreto saca su celular de la cartera y va jugando un juego de lógica. Dice que los viernes trata de no dormir para que no le afecte el sueño de la noche. El viaje se desarrolla con cierta calma, mientras Loreto se divierte, yo observo el paisaje. Son las 16:45 pm. y Loreto baja del bus despidiéndose y dándole un recado a Miriam, la auxiliar del bus. Me cuenta que la conoció viajando y que vende algunos productos (carne y huevos), que a veces le compra cuando va a su casa. La casa de Loreto está en la entrada de la villa, por lo que caminamos menos de 50 metros para llegar a su hogar. Antes de despedirnos, Loreto me cuenta qué hará cuando esté en su casa: Llego a la casa, me cambio de ropa, ahí pongo la mesa, tomamos once en familia, trato generalmente de que esté mi marido también, o sea trato de que estemos los cinco, que tomemos once en familia. Tomamos once, y después yo me preocupo de lavar la loza, y de cuidar a los chicos. Nos despedimos en la entrada de su casa.

Loreto, a diferencia de Francisco, constituye un caso de movilidad desarrollada en transporte público, con la connotación de cierto desagrado que representa este tipo dispositivo de transporte para los habitantes de ciudades intermedias menores (microbuses incómodos y de recorridos temporales relativamente extensos). La incertidumbre respecto a la modalidad de viaje (viajar de pie o sentado) merma la experiencia, lo que provoca un menor bienestar emocional (Handy y Thigpen, 2019) en lo que respecta a la organización del viaje. La espera y la lucha por asientos genera preocupaciones complementarias al desplazamiento. Adicionalmente, encontramos un factor extra respecto al caso anterior. En su condición de mujer, Loreto debe ocuparse de resguardar su integridad en el espacio público, proceso que evidencia también desigualdades de género desde la movilidad.

"La bicicleta me recrea, lo paso bien pedaleando para ir a trabajar". Freddy tiene cuarenta y ocho años, vive junto a su esposa en la población Alejandro Magnet de la comuna de Río Bueno. Es una casa que pudo comprar a través de un subsidio, es un lugar que tiene dos años de antigüedad, donde aún existe poco tránsito de personas. Casi a las 17:00 p.m. nos disponemos a ir a su lugar de trabajo. Para ello, preparamos los artefactos que Freddy instala en su bicicleta, destaca: celular amarrado al manubrio, bolsa con implementos de trabajo amarrado al manubrio, chalecos reflectantes y cascos que nos pondremos para viajar. Estamos dispuestos a empezar el recorrido (Figura 5).

Al principio avanzamos de manera pausada, pero luego de un par de minutos, para aprovechar la calle en bajada, empieza a aumentar la velocidad. Circulamos entre autos y camiones que circulan a alta velocidad. A Freddy se le ve acostumbrado, mientras yo intento disimular mi nerviosismo y adaptarme a los ritmos que propone él. El viaje transcurre sin mayores momentos de diálogo, los motivos se relacionan con la concentración que implica manejar bicicleta, aunque a ratos podemos alinear las bicicletas y cruzar palabras, estos instantes no duran más de un minuto y Freddy vuelve a pedalear con más fuerza, tomando el rol de "jefe de fila" en nuestro viaje.

Siempre canta cuando pedalea, no ocupa audífonos, son canciones cristianas. A medida que salimos de la ciudad podemos circular libremente por la pista de los vehículos. En eso, nos encontramos con otra bajada por donde vienen subiendo dos autos. Vamos por un espacio no habilitado para bicicletas, sino para automóviles. Adelantamos una bicicarro de trabajo. Ya se empieza a escuchar, ver y relacionar la presencia de camiones de carga. Dispositivos de transporte de contundente fuerza asimétrica en relación con una bicicleta y su cuerpo humano expuesto que la hace funcionar.

Estamos acercándonos al lugar de trabajo de Freddy, tenemos tiempo para intercambiar palabras, sensaciones sobre su viaje. La bicicleta, para Freddy, me recrea para 

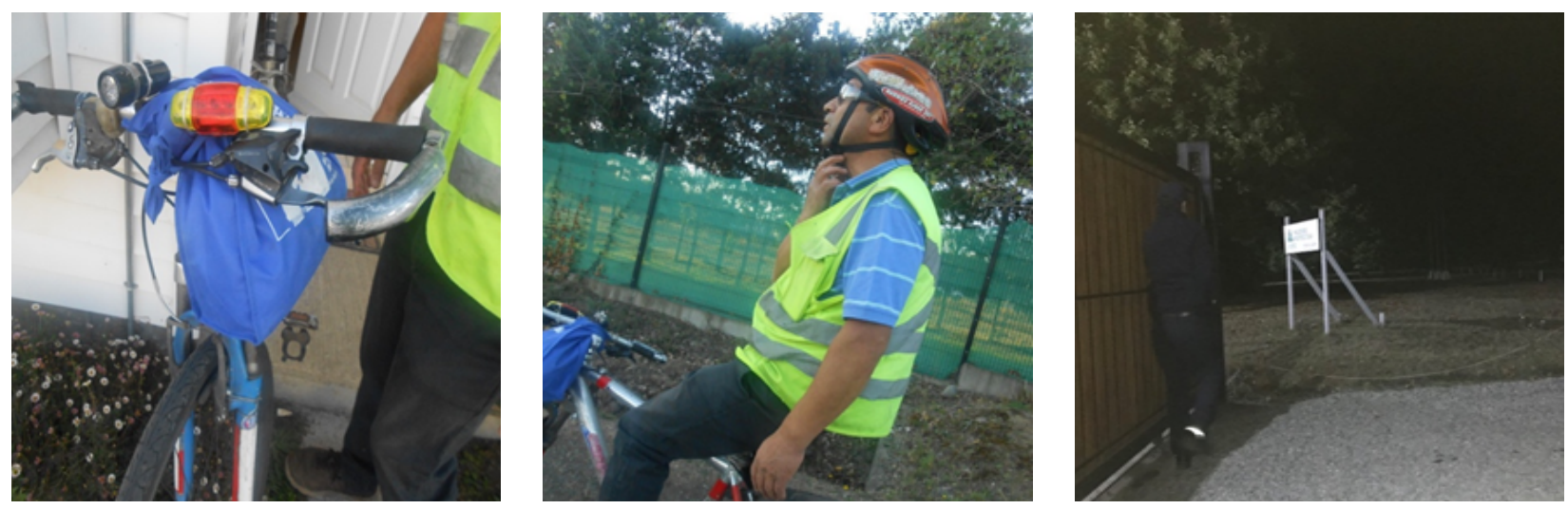

Figura 5. Secuencia del viaje de Freddy en bicicleta. Fuente: Colección personal.

ir al trabajo, genera una sensación de optimismo, se pasa bien y sirve para tomar buen aire. En cuanto a inconvenientes, dice: he quedado botado en la carretera. Se puede desinflar un neumático. Él anda con cámara de repuesto, y hay cosas que se pueden solucionar en el momento y otras no, es bueno que mi bicicleta sea desarmable ya que la puedo subir a una micro. Cosa que ha hecho, en esos casos. Para él, el clima no afecta la bicicleta, me pongo un buen traje de agua que tengo (...) y me vengo meta silbar (silba ahí) y cantando (...) hay que ser optimista en la vida.

Según Freddy, en bicicleta no se siente la distancia entre su casa y el lugar de trabajo, pero para ello hay que tener buena bicicleta. El recorrido lo hace todo el año, no obstante, la vuelta es más complicada. Hay menos visibilidad, por las orillas y todo lo que se transforma en una preocupación adicional. Cuando quedan 3 kilómetros para llegar, el sol empieza a caer.

Como Freddy trabaja para una empresa externa, la empresa de la forestal no lo incluye en el transporte que disponen para todos sus trabajadores. En sus viajes de larga distancia como este, plantea que se distrae mentalmente, toma aire limpio mientras avanza, eso lo satisface, y observa en tiempo presente como su organismo funciona. Dimensiona su musculatura, sus muslos, pantorrillas y caderas. Lo dejo en la entrada de su lugar de trabajo, así acordamos realizar el viaje de vuelta a las 20:00 p.m. aproximadamente. Yo estoy algo cansado, en Freddy no se ve muestra alguna de agotamiento físico.

Siendo las 19:55 p.m. salimos de su lugar de trabajo, ya es de noche y cruzamos la carretera con mucho cuidado, nos instalamos en la berma, en dirección contraria al flujo vehicular; por lo que la luz de los autos y camiones nos llega de frente. Yo me voy adelantito me dice. Aún sin avanzar, vemos que su bicicleta llevaba un sistema de luces por adelante y atrás, además, llevaba reflectante en el casco y chaqueta.

$\mathrm{Al}$ avanzar, Freddy pregunta por el nivel de cansancio, intento disimular y responder que es solo un poco. Vamos uno tras otro, como integrantes de un equipo de ciclismo, nos mantenemos siempre atento a su chaleco reflectante, mientras Freddy alerta: ahora hay que tomar precaución. Dejamos atrás el camino más transitado e ingresamos a una nueva calle, pasamos una plataforma-puente de cemento, $y$, es un tramo donde los camiones transitan a alta velocidad, lo que pone un poco más en riesgo nuestra integridad. Sin embargo, según Freddy, son calles tranquilas, no me meto al centro, me voy por el sector residencial, hago esta vuelta porque esta rutina es más relajada. Tengo suspensión fija para agarrar más velocidad. Entre los autos que circulan por detrás, nuestras sombras se reflejan hacia delante de las bicicletas. A esta hora ya se siente el cansancio y el asiento deja en mí ese dolor de quien no está acostumbrado a utilizar bicicleta cotidianamente, por lo que debo alternar entre estar sentado y pedalear parado. Siendo las 22:00 p.m. llegamos a las cercanías de la población donde Freddy reside, y nos acercamos a un almacén a comprar el pan para la once y el desayuno. Lo espero afuera, y él deja su bicicleta estacionada adentro del negocio, sin cadena. Realiza esta parada en el almacén diariamente, ya que llega antes que su señora que viene de Osorno.

Salimos del almacén con dirección a su casa, una vez ahí, se baja lentamente de la bicicleta debido al agotamiento manifiesto. Su casa esta oscura y lo único que se observa es 
su chaleco y las reflectancias de su bicicleta, producto de la poca luz que entrega la iluminaria pública de la población a esas horas de la noche. Lo dejo en la puerta de su casa y nos despedimos, deseándole un placentero descanso y pensando en lo agotado que están nuestros cuerpos.

El caso de Freddy se diferencia de la experiencia de Francisco y Loreto, no solo por el dispositivo de transporte utilizado, sino que también por la representación de Freddy respecto a la experiencia corporal, mental y espaciotemporal del viaje en bicicleta. Freddy representa una realidad que escapa de lógicas que plantean que vivir en la ruralidad y no contar con medios de transporte, conllevaría escenarios de exclusión social (Soder y Peer, 2018). La bicicleta emerge como una táctica de movilidad a contracorriente, que beneficia la salud psicológica y física del conmutante, no obstante, esconde lógicas de desigualdad social a partir de las escasas posibilidades de llegar a su lugar de trabajo sin este dispositivo de transporte. Aunque para Freddy la bicicleta es resignificada y revitalizada, también es un dispositivo escogido por obligación y no necesariamente una posibilidad dentro de muchas otras para desplazarse.

\section{Prácticas únicas y diferencias de movilidad}

En las experiencias y relatos de los tres participantes del estudio se evidencian diversos matices que permiten ahondar en las prácticas únicas y diferencias de movilidad de los conmutantes de La Unión y Río Bueno. Cada una de las rutinas está fuertemente influenciada por factores como medios de transporte utilizados, lugar de residencia, experiencias de viaje, objetos de viaje y rutinas cotidianas. Una primera distinción se origina en los medios de transporte utilizados, lo que reproduce desigualdades sociales entre los conmutantes (Cebollada, 2009; Santos, 2017). Francisco, Loreto y Freddy utilizan tres medios de transporte diferentes para acudir a sus lugares de trabajo. Francisco, quien posee automóvil particular, refleja la autonomía y comodidad en el desplazamiento, ya que es él quien organiza los tiempos y tiene control sobre los movimientos que realiza por las rutas disponibles. Francisco representa la noción de fluidez en el viaje, pues reproduce lógicas de instantaneidad en las prácticas de movilidad. Así, su independencia económica lo posiciona como una persona que puede elegir dónde, cuándo y cómo moverse por la ciudad (Keyes \& Crawford-Brown, 2018).

El caso de Loreto representa a la gran mayoría de los viajeros para quienes la utilización de transporte público es el medio de conexión fundamental entre su lugar de residencia y el lugar de trabajo. Loreto ha desarrollado diversas tácticas que le permiten afrontar las rutinas de viaje. Emergen compañeras de viaje, objetos, lugares y sitios que permiten sensaciones de mayor conformidad y disconformidad en el desplazamiento. El modo de viaje y su ubicación residencial afectan su sensación de bienestar (Handy \& Thigpen, 2019), esto se evidencia cuando identifica lugares inseguros, rutas que cambian producto de la sustitución del chofer habitual, largas esperas en terminales de microbuses y la aparición de agotamiento físico y mental producto de los constantes viajes en microbús. Todos estos factores mencionados, posicionan a Loreto como una conmutante que se ve enfrentada a las deficiencias, incomodidades, desigualdades de género y dependencia de la infraestructura pública de la movilidad. La situación de Freddy constituye experiencias de movilidad asociada a subjetividades representativas de momentos de libertad. El autoconocimiento del cuerpo, como propulsor determinante de sus movimientos y viajes, provoca en Freddy múltiples sensaciones durante las prácticas de movilidad: cansancio, ansiedad, libertad, preocupación, relajo, tranquilidad y resistencia corporal se funden como estados inherentes del papel de ciclista que viaja hacia el trabajo cotidianamente. Las afectividades de la movilidad (Jones \& Southcott, 2015) se tornan particularmente relevantes en Freddy, quien está en constante conexión con el medioambiente tanto en su papel de conmutanteciclista como en su rol de ciudadano y jefe de hogar.

La segunda distinción proviene de la organización del viaje, entendiendo este no solo como el tiempo de desplazamiento, sino como un proceso espaciotemporal que abarca la organización del viaje (previaje) y la actividad desarrollada una vez concluido el viaje (posviaje). En este sentido, las actividades y tiempos de Francisco, Loreto y Freddy son disímiles entre sí. Mientras Francisco constituye un caso de autonomía individual debido a su estilo de vida, Loreto desarrolla diversas actividades asociadas al cuidado del hogar desde que se levanta por las mañanas, y también por las tardes cuando concluye su jornada laboral. Por último, Freddy, en su posición de jefe de hogar, posee cierta autonomía respecto a las laborales del hogar, no obstante, carece de un medio de transporte particular alternativo a la bicicleta en caso de que se presenten inclemencias climáticas relevantes.

Los tres casos estudiados constituyen experiencias propias de la movilidad en el sur de Chile, donde factores culturales y económicos representan opciones y condiciones de viaje que se desarrollan en directa relación con las actividades cotidianas. El viaje por motivos de trabajo permite conocer percepciones y prácticas de movilidad que reflejan los matices de la movilidad. En este sentido, el viaje se 
vuelve un espacio percibido de múltiples maneras, donde las tácticas empleadas para llegar al trabajo obligan a redoblar recursos con el objetivo de cumplir activamente en los espacios productivos.

\section{Conclusiones}

Repensando la movilidad en las ciudades intermedias menores

El estudio de la movilidad en ciudades intermedias menores conlleva plantear escenarios particulares respecto al análisis de las experiencias de conmutación, en la que condiciones de semiruralidad y estilos de vida no metropolitanos confieren a las prácticas de desplazamiento características propias que se distancian del paradigma de la movilidad metropolitana.

En este sentido, los habitantes de La Unión y Río Bueno, como ejemplo de ciudades intermedias menores, desarrollan múltiples estrategias de movilidad en relación con la organización de viajes que implican la utilización de objetos, medios de transporte y rutas que hacen que esta tipología de movilidad se despliegue en base a experiencias que aglutinan aspectos como ritualización, afectividad respecto a las rutinas de viaje y las personas involucradas, y una noción del sacrificio como eje central de los viajes efectuados en dispositivos y rutas que no son del todo óptimas, lo que releva la noción del hábitat en territorios que no poseen una infraestructura que responda de manera coherente a las necesidades de movilidad de la población, lo cual genera sentimientos de frustración, preocupación y desagrado entre los conmutantes.

El presente artículo es una muestra de las contradicciones generadas en torno al desarrollo social armónico e integral entre las diversas ciudades del sur de Chile. Los resultados indican que las ciudades intermedias menores continúan sirviendo como ciudades dormitorio, donde sus habitantes necesitan de ciudades mayores para efectuar sus prácticas cotidianas. Así, el viaje pareciese ser un elemento central y constitutivo de los espacios de vida de los habitantes de ciudades menores, donde la práctica de movilidad se torna una actividad y necesidad que iguala a otras históricamente reconocidas como salud, educación, vivienda y trabajo. Los Estados subsidiarios en Latinoamérica durante las últimas décadas han diseñado políticas públicas respecto a las cuatro categorías enunciadas, discutiendo cómo cada una de ellas beneficia la vida cotidiana de los ciudadanos, sin embargo, la movilidad aún es una categoría tratada de manera incipiente y de alta vacancia. Creemos que posicionar la movilidad como un factor clave en la promoción de la calidad de vida y la participación social repercutirá considerablemente en el desarrollo social de los territorios en cuestión.

Un tercer aspecto está dado por el arraigo con el lugar habitado. Los conmutantes de ciudades intermedias menores muestran sentimientos de incondicionalidad respecto al lugar donde viven, más allá de las críticas que presentan ante las experiencias de viaje y lo incómodo que puede resultar en sus vidas cotidianas. El cambio de residencia a la ciudad donde trabajan no está entre sus planes, más aun, se visualizan viajando a largo plazo, lo que desecha la posibilidad de migrar a una ciudad de mayor rango. Esta complicidad con el territorio habitado está dada por las experiencias sociales que implica vivir en ciudades menores. Seguridad, confianza, cercanía y comodidad emergen como sentimientos fundamentales al momento de sopesar el cambio de residencia. Para los conmutantes, La Unión y Río Bueno entregan una mejor calidad de vida en la globalidad, y, como contraparte, el viaje cotidiano implica un sacrificio personal en pos del bienestar familiar.

En lo que respecta al estudio de la conmutación en áreas metropolitanas, se detecta que a partir de la localización del lugar de residencia y el lugar de trabajo, la configuración del mercado urbano está determinado por aspectos propios de la organización económica, demográfica y social de las ciudades latinoamericanas (Vizuet \& Soriano, 2008). Este quiebre entre lo metropolitano y lo regional se origina, ya que en que la perspectiva intrarregional las movilidades se desarrollan a tenor de dinámicas espaciotemporales de menor intensidad, aspectos rítmicos propios de la cultura local y una infraestructura de la movilidad de menor envergadura.

Por un lado, el viaje, al unir diversos espacios de la vida que trascienden la utilización de algún dispositivo de transporte, permite conocer y descubrir las lógicas de interacción social que se gestan al ritmo de sociedades en tránsito (Pellicer, Vivas-Elias, \& Rojas, 2013). No es casual que el giro de la movilidad esté fuertemente influenciado por las actividades laborales, ya que es uno de los factores determinantes que promueven la salida del hogar en pos de la conexión con actividades y lugares productivos. A partir de los resultados de esta investigación nos encontramos con realidades propias de territorios escasamente pesquisados, donde la movilidad resulta fundamental para acceder a los diversos espacios que entrega la ciudad para aquellos ciudadanos que en su entorno próximo no logran cubrir sus necesidades. De esta manera, la presente investigación aporta en el incipiente trabajo desarrollado por los estudios de la movilidad en 
ciudades intermedias menores, donde aspectos rítmicos y territoriales inciden en las experiencias de conmutación. Por otro lado, el trabajo, si bien no es la única actividad que ha sido estudiada por los investigadores de la movilidad, permite conocer desigualdades, exclusiones, precariedades y diversos síntomas del modo de vida actual, tornándose un eje fundamental en lo que respecta al conocimiento de la experiencia única y diferenciada de los conmuters en sociedades en movimiento. Creemos que las dimensiones movilidad-trabajo en el desarrollo de la vida cotidiana desde la afectividad (Dorow et al., 2017) constituyen núcleos articuladores y centrales en la conmutación intrarregional de habitantes de pequeñas ciudades del sur de Chile.

Finalmente, se considera que este tipo de investigaciones aporta nuevos puntos de entrada para analizar las experiencias de movilidad en territorios atravesados por la semiruralidad, movilidades interurbanas y factores culturales propios del sur de Chile. El análisis de la conmutación en el sur de Chile implica considerar los factores socioculturales que emergen en las rutinas cotidianas; ritmos, tiempos, actividades y lugares se vuelven factores distintivos de esta tipología de movilidad.

\section{Referencias bibliográficas}

Bauman, Z. (2003). Modernidad Liquida. Madrid: Fondo de la Cultura Económica.

Blanchard, O., Deguen, S. \& Kihal, W. (2018). Does residential mobility during pregnancy induce exposure misclassification for air pollution? Environmental Health, 17- 72. https://doi.org/10.1186/ s12940-018-0416-8

Bole, A. (2004). Daily mobility of workers in Slovenia. Acta Geographica Slovenica, 44, 25-45.

Bordonaro, L. (2018). Entrevista a Noel B. Salazar, unidad de investigación sobre Movilidades Culturales (CuMoRe). Revista de Antropología Iberoamericana, 13,3, 315-331.

Calonge, F. (2017). Estar cerca en la lejanía. El surgimiento de los entornos de vida en una periferia. Athenea Digital. Revista Pensamiento E Invest. Soc. 17(2), 149-173. https://dx.doi.org/10.5565/rev/ athenea. 1761 .

Canales, A. \& Canales, M. (2016). Trabajo, territorio y movilidad cotidiana en Chile. Un estudio comparativo según tipos de conmutación laboral. VII Congreso de la Asociación Latinoamericana de Población e XX Encontro Nacional de Estudos Populacionais, a celebrarse, Foz do Iguaçu, Brasil.

Canales, A, Canales, M. y Hernández, H. (2018). Trabajo y territorio en el nuevo agro chileno. Un estudio de commuters en tres comarcas del Valle Central. Eure, 44(131), 5-27.

Cebollada, A. (2009). Mobility and labour market exclusion in the Barcelona Metropolitan Region. Journal of Transport Geography, 17 (3), 226-233.

Cresswell, T. (2006). On the Move. London: Routledge.

Cui, B., Boisjoly, G., El-Geneidy, A.\& Levinson, D. (2019). Accessibility and the journey to work through the lens of equity. Journal of Transport Geography, 74, 269-277.

Delclos, J. \& Miralles, C. (2017). Suburban travelers pressed for time: Exploring the temporal implications of metropolitan commuting in Barcelona. Journal of Transport Geography, 65, 165-174.

Dorow, S., Roseman, S. \& Cresswell, T. (2017). Re-working mobilities: Emergent geographies of employment-related mobility. Geography Compass, 11. https://doi.org/10.1111/gec3.12350

Espinoza, J. (2013). Espacios objetivos y subjetivos de la movilidad cotidiana urbana. Revista Cartográfica, 89, 103-118.

Garretón, M. (2012). Desigualdad espacial y utilidad social: esfuerzos de movilidad y accesibilidad en el Gran Santiago. Territorios, 25, 35-64.

Gimenez-Nadal, I. \& Molina, J. (2018). Daily feelings of US workers and commuting time. Boston College Working Papers in Economics, 967. Boston: Boston College Department of Economics.

Handy, S. \& Thigpen, C. (2019). Commute quality and its implications for commute satisfaction: Exploring the role of mode, location, and other factors. Travel Behaviour and Society, 16, 241-248. https://oi. org/10.1016/j.tbs.2018.03.001

Imilán, W., Jirón, P.\& Iturra, L. (2015). Más allá del barrio: habitar Santiago en la movilidad cotidiana. Revista Antropologías del Sur, 3, 87-103. 
Jiménez, V., Hidalgo, R., Campesino, A. \& Alvarado, V. (2018). Normalización del modelo neoliberal de expansión residencial más allá del límite urbano en Chile y España. EURE (Santiago), 44(132), 27-46. https://dx.doi.org/10.4067/s025071612018000200027

Jirón, P. (2010). On becoming 'la sombra/the shadow'. En Monika Buscher, John Urry y Katian Witchger (eds.), Mobile Methods, 36-53. Routledge: Londres.

Jirón, P. \& Mancilla, P. (2013). Atravesando la espesura de la ciudad: vida cotidiana y barreras de accesibilidad de los habitantes de la periferia urbana de Santiago de Chile. Revista de geografia Norte Grande, 56, 53-74. https://dx.doi.org/10.4067/ S0718-34022013000300004

Jirón, P. \& Imilán, W. (2015). Embodying flexibility: experiencing labour flexibility through urban daily mobility in Santiago de Chile. Mobilities, 10(1), 119135 .

Jones, C. \& Southcott, C. (2015). Mobile Miners: Work, Home, and Hazards in the Yukon's Mining Industry. The Northern Review, 41, 111-137.

Keyes, A. \& Crawford-Brown, D. (2018). The changing influences on commuting mode choice in urban England under Peak Car: A discrete choice modelling approach. Transportation Research, 2018, 167-176.

Lazo, A \& Carvajal, D. (2017). Habitando la movilidad: El viaje en lancha, los objetos y la experiencia de la movilidad en el archipiélago de Quinchao, Chiloé. Revista Austral de Ciencias Sociales, (33), 89-102. https://doi.org/10.4206/rev.austral.cienc.soc.2017. n33-06

Lazo, A. \& Carvajal, D. (2018). La movilidad y el habitar chilote. Cambios, rupturas y continuidades en las prácticas de movilidad cotidiana de los habitantes del archipiélago de Chiloé, en el sur austral de Chile. Chungará, 50(1), 145-154. https://dx.doi. org/10.4067/S0717-73562018005000203

Lobo, C., Cardoso, L., Almeida, I. L. de \& García, R.A. (2017). Mobilidade pendular e a integração metropolitana: uma proposta metodológica para os municípios da Região Metropolitana. Revista Brasileira de Estudos de População, 34(2), 321-339. https://dx.doi.org/10.20947/S0102-3098a0013
Litman, T. (2016). Land use impacts on transport. Victoria Transp. Policy Inst, 86. https:// dx.doi. org/10.1007/978-3-642-54876-5

Mateu, J., Seguí, J. \& Ruiz, M. (2017). Mallorca $\mathrm{y}$ sus dinámicas metropolitanas: proximidad $\mathrm{y}$ movilidad cotidiana en una isla-ciudad. EURE (Santiago), 43(129), 27-47.

Maturana, F. \& Rojas, A. (2015) . Ciudades intermedias en Chile Territorios olvidados. Santiago de Chile: RIL Editores.

Maturana, F, Rojas, A. \& Salas, L. (2018). Dinámicas espaciales y transición hacia la articulación de espacios metropolitanos. Es caso de Temuco y su hinterland. Cuadernos Geográficos, 57(1), 132-154.

Newhook, J. T., Neis, B., Jackson, L., Roseman, S. R., Romanow, P. \& Vincent, C. (2011). EmploymentRelated Mobility and the Health of Workers, Families, and Communities: The Canadian Context. Labour / Le Travail, 67, 121-156.

Pellicer, I., Vivas-Elias, P. \& Rojas, J. (2013). La observación participante y la deriva: dos técnicas móviles para el análisis de la ciudad contemporánea. El caso de Barcelona. EURE, 39(116), 119-139. https:// dx.doi.org/10.4067/S0250-71612013000100005

Riquelme, H. \& Lazo., A. (2019). Trazando rutinas: el papel del ferrocarril en las prácticas cotidianas y movilidades interurbanas de habitantes de La Araucanía, Chile. urbe Revista Brasileira de Gestão Urbana, 11. https://dx.doi.org/10.1590/21753369.011.002.ao02

Salazar, G., Fonck, M., y Vergara, L. (2018). Ciudades intermedias: dinámicas de intermediación desde la noción de lugar. El caso de la región de la Araucanía, Chile. Revista de geografia Norte Grande, 70, 109130.

Santos, S. (2017). Mobility and spatial planning in the Lisbon Metropolitan area. Finisterra, 11, 57-72.

Shareck, M., Froholich, K. \& Kestens, Y. (2014). Considering daily mobility for a more comprehensive understanding of contextual effects on social inequalities in health: a conceptual proposal. Health Place, 154-160. https://doi: 10.1016/j. healthplace.2014.07.007 
Sheller, M. (2014). The new mobilities paradigm for a live sociology. Current Sociology Review, 62(6), 789-811.

Sheller, M. \& Urry, J. (2016). Mobilizing the new mobilities paradigm. Applied Mobilities, l(1).

Soder, M. \& Stefanie P. (2018). The potential role of employers in promoting sustainable mobility in rural areas: Evidence from Eastern Austria. International Journal of Sustainable Transportation, 12(7), 541551. https://doi: 10.1080/15568318.2017.1402974

Trpin, V. \& Rodríguez, M. (2015). Mercados de trabajo y movilidad de trabajadores de origen chileno en el norte de la Patagonia. Polis (Santiago), 14(41), 517-537. https://dx.doi.org/10.4067/S071865682015000200030

Valdés S., X., Godoy R., C.G. \& Mendoza A., A. (2017). Acción colectiva y resistencia: asalariadas agrícolas en Chile frente a la precarización laboral. Izquierdas, 35, 167-198. https://dx.doi.org/10.4067/ S0718-50492017000400167

Venturini. J. \& Castro, H. (2018). La espaciotemporalidad de los trabajadores agrarios transitorios. Notas para un abordaje teórico-conceptual y metodológico. Eutopía, 14, 63-82.

Vizuet, I. \& Soriano, G. (2008). Mercado de trabajo y movilidad en la ciudad de México. Mundo Siglo XXI. Revista del Centro de Investigaciones Económicas, Administrativas y Sociales del Instituto Politécnico Nacional, 11, 45-56.

\section{Agradecimentos}

Los autores agradecen a Conicyt-Fondecyt por el financiamiento del proyecto 11171028 "La movilidad en su ambiente: Etnografía de los conmutantes de las ciudades de Osorno y Puerto Montt”. 